\title{
VIVIENDA Y VIDA PRIVADA: LA TRANSFORMACIÓN DE LOS CONCEPTOS POR LA ACCIÓN EVANGELIZADORA DE LA COMPAÑÍA DE JESÚS (PROVINCIA JESUÍTICA DE PARAGUAY, 1604-1767)
}

POR

\author{
NORBERTO LEVINTON
}

Argentina

\section{ResUMEN}

El autor estudia, desde el punto de vista arquitectónico, la evolución de las viviendas entre los indios guaranies. Observa cómo las técnicas introducidas entre ellos por los jesuitas implicaban cambios en la concepción de la vida doméstica.

\section{Anstract}

Housing and private life (Jesuit province of Paraguay, 1604. 1767)

The autor studies the evolution of houses form between Guaranies indians from the architectural point of view. He remarks how tecnics introduced by Jesuits imply changes in the idea of the domestic life.

\section{INTRODUCCIÓN}

La historiografia de la arquitectura de las Misiones Jesuíticas ha reducido su interpretación de la vivienda misional, a la configuración de un proceso evolutivo.

Missionalia Hispanica Hispania Sacra 49 (1997) 
Este proceso se bastaría en la concepción de una mecánica asociación entre la planta rectangular y alargada de la vivienda indigena a una convivencia promiscua de la llamada familia extensa, situación que al ser transformada por la acción de la Compañía de Jesús, dispondría la compartimentación de la vivienda y la definición de las familias celulares.

Esta caracterización es inicialmente sugerida por Buschiazzo', en 1956, cuando refiere que «el indio guaraní, acostumbrado a vivir en sus "ocas", enormes chozas donde se albergaban tribus enteras, s6lo admitio el nuevo régimen a condición de vivir toda la familia en un mismo local...»

El trabajo de Buschiazzo, que fue pionero en el estudio de la arquitectura de las Misiones Jesuíticas, fue escrito en un momento en que no abundaban los estudios etnológicos que pudieran aportar categorías particulares para los grupos étnicos investigados.

Buschiazzo no cita la fuente sobre la cual sustenta su afirmación y además, posteriormente, los estudios etnológicos darán cuenta de una mayor complejidad en las estructuras sociales guaraníes.

En 1977, De Paula ${ }^{2}$ expresa que «la estructura básica de la maloca (vivienda indígena) subsistio durante el período Jesuítico, con la incorporación de tabiques internos para dividir en habitaciones unifamiliares...»

Luego, en 1993, el mismo historiador ${ }^{3}$ completa y aclara su interpretación, definiendo a la vivienda indígena como «multifamiliar» y asociado este concepto a «familias poligámicas, compuestas por gran cantidad de personas convivientes en una misma casa alargada...»; que luego de la acción evangelizadora de los sacerdotes jesuitas «se transformaron en matrimonios monogámicos, con dos o tres hijos cada uno, en habitaciones unifamiliares que resultaron de la compartimentación de aquellas casas alargadas en espacios internos más pequeños, que por fuera conservaban su proporción habitual...»

Es importante revisar las fuentes que prevalecen en el autor, ya que partiendo de Ruiz Díaz de Guzmán y Del Barco Centenera, cita esporádicamente a las Cartas Anuas desde 1632 y pasa a del Techo (que llega a Buenos Aires el 28 de noviembre de 1640) y a Charlevoix (que nunca estuvo en América y cuyo trabajo corresponde a mediados del siglo Xvill, Es decir, no trabaja sobre relatos directos de la primera etapa de evangelización, que consideramos para-

I BuschIZZO, MARIO J., «La arquitectura de las Misiones del Paraguay, Moxos y Chiquitosm, en Historia del Arte Prehispanico, ed. Salvat, Barcelona, 1956.

2 DE PAULA, ALBERTO, «Argentina prehispánica: transctulturación y mestizaje», en Summa N." 10, Buenos Aires, marzo 1977.

3 De Paula AlberTo, «La Arquitectura de las Misiones del Guayra», en Las Misiones Jesufticas del Guayrá, ed. Manrique Zago, Buenos Aires, 1993. 
digmática, en la cual fueron fundadas las primeras reducciones (entre 1609: fundación de San Ignacio Guazú a 1631: éxodo del Guayrá). Además, toma como referencia a Canals Frau para la interpretación etnológica (en una edición de 1953), un trabajo cualitativamente anterior a la producción de importantes investigadores, como Meliá, a quién cita mínimamente.

Estos investigadores (Susnik, Schaden, Cadogan, Bartolomé, Perasso y otros) han contribuido a definir ciertas categorías sociales indígenas que utilizaremos en este análisis. Como tekó' $a$ ' o aldea, que era formada por la asociación, por parentesco político de los teyy, que a su vez era la estructura macrofamiliar patrilineal y al mismo tiempo la Casa Comunal, una conjunción sociohabituacional, que conformaba la conciencia del orevá (nosotros exclusivistas) 4 .

Volviendo a De Paula, entendemos que confunde lo «multifamiliar» con la macrofamilia, familia extensa o teyy, de los grupos étnicos del tronco lingüístico tupí-guaraní y desconoce que la poligamia era inherente exclusivamente a los caciques ${ }^{5}$, relacionándose por este medio poder social y poder económico (la posesión de mujeres tenía que ver con el intercambio o eran utilizadas para la captación de brazos).

Además el esquema monogámico era prevalente, como lo afirma el Padre Antonio Ruiz de Montoya SJ, en una Carta Anua ${ }^{6}$.

Ramón Gutiérrez ${ }^{7}$, en 1983, se refiere a las viviendas indígenas como «cabañas colectivas que tenían 4,5 metros de ancho por hasta 50 metros de largo, con un techo redondo como la bóveda de una bodega, hecha de hojas de palmera con tres puertas..." Su referencia proviene de la obra de Natalicio González (una edición de 1948), que a su vez cita a Hans Staden (explorador alemán del siglo XVI), González califica a la vivienda indígena de colectiva y promiscua $^{8}$ y Gutiérrez coincide con este punto de vista, sumándose a los historiadores que entienden la transformación de la vivienda indígena como la

4 SUSNIK, BRANISLAVA, «La cultura indigena y su organización social dentro de las Misiones Jesuíticas», en Sup. Antropológico, vol. XIX, N. 2, Universidad Católica, Asuncion, diciembre 1984.

5 MeLIA BARTOMEU, SJ, «El modo de ser Guarani en la primera documentación Jesuítica (1954-1639)", en El Guarant Conquistado y Reducido, Centro de Est. Antropológicos de la Univ. Católica, Asunción, 1988.

6 RUIZ DE MONTOYA, ANTONIo SJ, Carta Anua de julio de 1628. Refiriéndose a los Gulachos: «tienen todos una lengua y una sola mujer aunque prestada porque no tienen fixo un matrimonio como el Guaraní y con menos estabilidad porque el Guarani tiene sujeción en la mujer para retenerlo o despedirla...", en BARRIOS PINTOS, ANIBAL, Historia de los pueblos orientales.

7 GuTIÉREZ, RAMón, Evolución Urbantstica y Arquitectónica del Paraguay (1537-1911), ed. Comuneros, Asunción, 1983.

8 GonzÁlez, NATAlicio, Proceso y formación de la cultura paraguaya, ed. Guarania, Asuncion, 1948. 
expresión de que «el objetivo de los jesuitas tendía fundamentalmente a consolidar la familia monogámica.... $\otimes^{9}$

Es decir, que se persiste en interpretar el proceso sólo como «un ordenamiento social» asimilándose las costumbres antiguas a una supuesta mezcla o confusión (promiscuidad).

Sin embargo, Gutiérrez coincide con Cayetano Bruno ${ }^{10}$ en afirmar que el acostumbramiento al nuevo sistema llevó casi un siglo. Esta observación, sustentada en documentos emitidos por diferentes padres provinciales ${ }^{13}$ que reclaman la partición interior de la vivienda, podría indicar la complejidad del proceso de transformación de la forma de habitar pero al misme tiempo una versión jesuítica diferente a lo interpretado hasta el momento, una conceptualización que constituiría el objetivo de este trabajo.

Mi intención es explicar cómo la vivienda indígena y la vivienda misional se inscriben en dos sistemas de significación diferentes y describir la transición de un sistema al otro como producto de ese complejo proceso de continuidad y rupturas.

Como el concepto de vida privada (privado: del latín privatus) sería definido por lo que se hace familiar y domésticamente (de domus: casa), intentaremos delimitar históricamente estas categorías entre los Guaraníes, antes y después de la evangelización.

Primeramente, a través de los relatos de diversos cronistas que mantuvieron contactos con grupos étnicos del tronco lingüístico tupí-guaraní, describiremos las viviendas indígenas.

En segunda instancia analizaremos su tipología y el concepto de familia que le es pertinente, a través de los testimonios de los sacerdotes jesuitas.

Por último, procuraremos explicar la transición de la vivienda indígena a la vivienda misional, a través de los cambios que sufrieron estas categorías.

\footnotetext{
9 GUTí́rRez, Ramón, Op. cit.

14 BRUNO, CAYetano, Historia de la Iglesia en la Argentina, Inst. Salesiano de Artes graficas, Buenos Aires, 1968.

11 Bruno, Cayetano, Op. cit., nombra al Padre Andrús de Rada (visitador) en 1667 y luego menciona al Padre Provincial Ignacio de Frías en 1699 y al Padre Provincial Juan Bautista de Zea o Cea en 1719, reclamando más viviendas y la partición de las mismas. 


\section{DE LA VIVIENDA INDÍGENA A LA YIVIENDA MISIONAL (CONTINUIDADES Y} RUPTURAS)

Cada elemento arquitectónico que conformaba la vivienda indígena estaba relacionado con el medio natural, los hábitos de subsistencia y la estructura social de los grupos étnicos del tronco lingüístico tupí-guaraní.

En forma análoga, podemos afirmar que cada modificación introducida por los sacerdotes de la Compañía de Jesús generaba toda una serie de cambios encadenados, no sólo desde el punto de vista social y religioso, sino también inherentes específicamente a los lenguajes arquitectónicos y a los sistemas constructivos tradicionalmente utilizados por los indígenas.

\section{a) El espacio interno}

Las características de la vivienda indígena pueden definirse de manera genérica, con la amplitud que posibilita el concepto de tipología.

Este instrumento conceptual se hace necesario, en la medida que las fuentes documentales difundidas hasta el momento, no son suficientemente precisas en la diferenciación de las subculturas guaranies.

Sin embargo, es posible determinar una serie de elementos que configuran la etnicidad ${ }^{12}$ desde el punto de vista arquitectónico, de los grupos étnicos del tronco lingüístico tupí-guaraní.

Me refiero en principio a las plantas rectangulares y longitudinales cuyas medidas difieren entre los guaraníes y los tupinambá.

Dionisio González Torres ${ }^{13}$ coincide con Alfred Metreaux ${ }^{14}$ en adjudicar 50 metros de largo por 5 a 6 metros de ancho para las viviendas guaranies; de 100 a 150 metros de largo por 15 metros de ancho a las viviendas tupinambá.

De todas maneras, suponemos que el esquema tipológico pudiera haber variado en función de diversidades regionales, como materiales de recolección

12 «Ñande Reko* es traducido por Meliá como «nuestro modo de ser» y se relaciona cstrechamente con «tekoha», que quiere decir: lugar de modo de ser (relaciones económicas, relaciones sociales y organización política-religiosa esenciales para la vida guarani), de MELÁ BARTOMEU, SJ, «El modo de ser guaraní en la primera documentación jesútica», en El guarani conguistado y reducido, Centro de Est. Antrop. de la Univ. Católica, Asunción, 1988.

1.3 GONZÁlezZ TORRES, DtoNisio, Cultura Guaraní, Litocolor, Asunción, 1991.

14 METREAUX, ALJRED, The Guarani, en Handbook of South American Indians, Smithsonian Institution, Washington, 1948. 
disponibles, escala de las macrofamilias, contactos interétnicos, presiones esclavistas y otros factores como las posibilidades alimentarias ${ }^{15}$.

Una de las fuentes de Metreaux, el monje capuchino Claude D'Abbeville ${ }^{16}$, que convivio con los Tupinambá hacia fines del siglo XVI, afirma que «esas grandes cabanas não têm separação alguna. Tudo se ve de ponta a ponta, mas năo ha confussao alguna, pois cada chefe de familia vive em seu canto com suas mulheres, seus filhos, seus escravos e seus moveis...»

El mismo sacerdote se encarga de aclarar que «embora a poligamia seja permitida aos homens, satisfazem -se êles, en sua maioria, com uma só mulher. Somente a fim de ganhar certo prestígio tomam muitas mulheres; säo nesse caso julgados grandes homens e se tornan os principais das aldeias...»

La misma visión expresa el Padre Cardim con respecto a otro grupo étnico del mismo tronco lingúístico ${ }^{17}$, lo que nos permite sostener que la vivienda en función de tal, no era vivida como una casa colectiva sino que existía una compartimentación virtual del espacio para cada jefe de familia con su núcleo.

Además la problemática de la poligamia es restringida a los caciques ${ }^{18}$, atribuyéndosele una categorización social más que una connotación de liberalidad sexual que pudiera tender a la promiscuidad.

Otro cronista del siglo XVI y antiguo monje franciscano, André Thevet ${ }^{19}$, también reafirma estos dichos, cuantificando la superficie ocupada por cada grupo familiar en tres brazas de largo (1 braza $=2$ varas) por el ancho de la vivienda.

Estas medidas eran muy cercanas a las que posteriormente tendrían las unidades de vivienda en las misiones jesuíticas: 7 varas $x 7$ varas $^{20}$.

\footnotetext{
is \&La base de las casas comunales era generalmente rectangular siendo las viviendas circulares de los Chiriguanos del siglo XVI y las octogonales de los Guarayos transmigrados excepcionales...», de SuSNIK, Branisl.Ava, «Los aborfgenes del Paraguay», vol. IV, Cultura Material, Museo EtnogAndrés Barbero, Asunción, 1982.

16 D'AbBeville, Claude, Historia da Missoo dos Padres Capuchinos na tha do Maranhao $e$ terras circunvizinhas, Martins Editora S.A., Sao Paulo, 1945. 1978.

17 CARDim, Fernao SJ, Tratados da terra e Gente do Brasil, Companhia Ed. Nacional, S/L,

18 Ver al respecto: MELĹA BARTOMEU, «EI modo de ser Guaraní en Ja primera documentación Jesuitica (1954-1639)", en El Guarant Conquistado y Reducido, op. cit.; MAEDER, ERNESTO, La familia en el mundo Guarani; MASHNSHNEK, CELAA O., La familia indigena tradicional, un acerca. miento hermenéutico a sus valores esenciales; RíPODAS ARDANAZ, DAISY, El matrimonio en Indias, Fund. para la Educación, la Ciencia y la Cultura, Buenos Aires, 1977.

19 THEVET, ANDRÉ, La Cosmographie Universelle (1575), PUF, Paris, 1953.

20 CARDiEl, JosÉ SJ, Costumbres de los Guaranies (1764), Lib. Gral, de V. Suárez, Madrid, 1919.
}

Missionalia Hispanica

Hispania Sacra 49 (1997) 
Siguiendo este razonamiento, es oportuno revisar cómo veían los sacerdotes jesuitas la vivienda indígena.

En el año de 1611, en la reducción de San Ignacio Guazú, Roque González. de Santa Cruz escribe que «habiendo de hacer pueblo estos pueblos, digo indios, nos pareció lo hiciesen con buen orden para irlos poniendo en buena policía y quitar muchos inconvenientes que hay en unas casas largas, que tienen los indios en toda la sierra.... $)^{21}$

El jesuita encuentra que la costumbre antigua provoca un perjuicio, por lo cual es necesario producir una modificación, lo que él denomina en otra carta de 1613 «construirlo a la manera de los pueblos de españoles, para que cada uno tenga su casa con sus límites determinados y su correspondiente cerca...»

Se clarifica la novedad, ya que afirma que se dispone para «impedir el fácil acceso de la una a la otra como era antes...»

Pero lo más importante es la explicitación de lo que el padre González de Santa Cruz SJ entiende como los «inconvenientes» que la vivienda indígena proporcionaba. El tropiezo consistía en la «inevitable ocasión para las borracheras y otros crímenes..., ${ }^{22}$

De ninguna manera se refiere el padre jesuita a una situación de mezcla o confusion (promiscuidad), lo que es ratificado por una carta anua de 16261627, que refiriéndose a la reducción de Nuestra Señora de la Concepción dice que «cada una (casa) (y lo mismo usan en todo el Paraguay) es una gran pieza donde vive el Cacique con toda su parcialidad (...) ni tienen otra división o apartamiento estas casas que unos pilares que corren por medio del edificio a trechos y sirven para sustentar la cumbre y de señalar el término de la vivienda de cada familia, que es el espacio que hay entre uno y otro pilar, uno de esta banda y otro de aquella.... ${ }^{23}$

Como se aprecia en esta carta anua, la compartimentación virtual, previa al contacto con los jesuitas, es ratificada por el padre provincial Mastrillo Durán.

Es decir, que en base a estos documentos, coincidimos con la historiografia mencionada, en cuanto a que la modificacion que se ha realizado en la vivien-

21 GonzÁlez de SANTA Cruz, Roque SJ, de Carta Anua del Padre Diego de Torres (8 de abril de 1614), en Documentos para la Historia Argentina, Tomo XIX, Facultad de Filosofia y Letras, Buenos Aires, 1929.

22 GONZÁlez de SANTA CrUZ, ROOUE SJ, de Carta del 8 de octubre de 1613, en San Ignacio Guazú en TESCHAuER, CARLos, Vida e obra de Venerabel $R$. González de Santa Cruz, Livraria Americana, Rio Grande do Sul, 1913.

23 Mastrillo DuRÁN, Nicolás, SJ, de Carta Anua del 12 de noviembre de 1628 en Documentos para la Historia Argentina, Tomo XX, Facultad de Filosofia y Letras, Buenos Aires, 1929. 
da consiste en la materialización por intermedio de algún tabique, de la división entre familias.

Pero, desde mi punto de vista, no debe entenderse este cambio como el pasaje de la poligamia a la monogamia, según sostiene De Paula, ni siquiera como la ruptura de los antiguos lazos de parentesco que unían la macrofanilia de acuerdo a la opinión de Paula Caleffi'i24.

En principio, entiendo que la búsqueda de los jesuitas se orienta a definir un hábitat que, desde su propia entidad, los acerque a la sociedad colonial («al modo que los españoles...», dice el padre Roque González de Santa Cruz), creando las condiciones para realizar conjuntamente, los sacramentos del matrimonio y del bautismo ${ }^{25}$.

Más que la definición de la familia celular, que salvo el caso de los caciques, ya está dada previamente, la vivienda como ámbito de convivencia de la familia patriarcal o conyuga ${ }^{26}$ es la realización misma del concepto de vida privada (la familia y el espacio que le es pertinente, la vivienda) ${ }^{27}$.

Por otro lado, hay una continuidad de la estructura del Teyy y se mantienen los lazos de parentesco, en una vivienda alargada, compuesta por varios módulos de viviendas (cinco módulos o lances, de a veinte pies cada uno, a razón de 1 pie $=1 / 3$ de vara $)^{28}$.

Así lo demuestra la lectura de los padrones existentes en el Archivo General de la Nación, en Buenos Aires, en los cuales puede seguirse la continuidad de los cacicazgos de San Ignacio Cuazú entre 1609 y 1657 (AGN, Sala IX, 187-7) y entre 1657 (AGN, Sala IX, 45-3-10) 2929. $^{2}$.

Lo que aparece como una disposición ruptural de la vivienda misional con respecto a la vivienda indígena, es el abandono de la pluri-funcionalidad que tenía esta última.

24 CALEFF, PAULA, $O$ tracado das reducoes Jesulticas e a transformaçao de conceitos culturais, en Veritas V. 37, $\mathbf{N}^{\circ} 145$, Porto Alegre, 1992.

25 MARTINI, MÓNICA, El indio y los sacramentos en Hispanoamérica Colonial, PRHISCOCONICET, Buenos Aires, 1993.

26 FRÍAS, SUSANA R., La familia en la época hispánica.

27 epor su parte Nebrija, en el vocabulario latino-español traduce la familia española como domus... CHACÓN IIMÉNEZ, FRANCISCO, «La familia en España: una historia por hacem, en La familia en la Espafia Mediterránea, Ed. Crítica (Grijalbo), Barcelona, 1987.

28 GONZÁLEZ DE SANTA CRUZ, ROQUE SJ, «Op. cit.

29 En AGN, Sal IX 18-7-7, Empadronamiento de San Ignacio Guazú en 1657 aparece por ejemplo. Thomás Arapisandú, quien no puede ejercer el Cacicazgo por ser menor de edad y soltero y lo hace interinamente su tío. A este futuro cacique lo suponemos descendiente del Cacique fundador de la reducción, Arápisandú.

Missionalia Hispanica

Hispania Sacra 49 (1997) 
Sostenemos que, en ciertas ocasiones, la planta longitudinal debía funcionar como una totalidad, un espacio único.

Al respecto, Staden menciona la ingestión grupal de bebidas y danzas dentro de las viviendas indígenas ${ }^{30}$. También Thevet, como prolegómeno de un rito antropofágico, describe una danza entre hombres y mujeres dentro de las viviendas $^{31}$. De los escritos del Padre Fernao Cardim ${ }^{32}$ destacamos las plegarias que hacía un uprincipal...» por la mañana exhortando a su gente a hacer las rozas y excitarlos para la guerra.

Estos testimonios conformarían los antecedentes históricos de la explicación que produce Schaden ${ }^{33}$ respecto a la estructura del espacio interno de la vivienda indígena. Este investigador afirma que la ausencia de soportes para la cumbrera, permite a los indígenas kayová realizar ciertas danzas de las fiestas de chicha dentro de las viviendas.

En este contexto de significación, cobra sentido la frase del padre Roque González de Santa Cruz, acerca de que la falta de divisiones internas era «inevitable ocasión para las borracheras y otros crímenes...»

\section{b) La estructura}

La vivienda denominada como og jekutu (og: casa / je: se / cutu: clava), que quiere decir casa de palos hincados, es una tipología constructiva cuya continuidad histórica está certificada desde los relatos de experiencias misioneras hasta las descripciones de estudios etnológicos actuales.

Esta estructura de palos hincados, descrita en la carta anua del padre Mastrillo Durán como «unos pilares que corren por medio del edificio a trechos y sirven para sustentar la cumbre.... ${ }^{34}$, podía sostener un techo-pared arqueado, dándole a la casa una forma similar a una canoa invertida ${ }^{35}$.

Con algunos cambios formales describe la actual vivienda de los indígenas avá-kué-chiripá, perasso y vera; también es el sistema utilizado por los pañ', según el trabajo del padre Franz Müller y; por los cayovâ, con el mismo nom-

30 STADEN, HANS, Vera historia y descripción de un pats de las salvages desnudas feroces gentes devoradoras de hombres situado en el nuevo mundo (1545), Museo Etnográfico, Buenos Aires, 1944.

3I THEVET, ANDRÉ, Op, cit.

32 Cardim, Fernao $\$$, Op. cit.

33 SCHADEN, BGON, Aspectos fundamentais da Cultura Guarant, Difusao Europeia do Livro, Sao Paulo, 1962.

34 MASTRILLO DURÁN, NiCOLÁs SJ, Op. cil.

3 MŪllER, FRANZ, Etmografia de los guaraní del Aho Paraná, Buenos Aires, Cehass, 1989. 
bre de ogadjekutú (casa fincada) (kutú: fincar, cutucar) como lo afirma Egon Schaden ${ }^{36}$.

En sus construcciones los jesuitas implementaron un dispositivo constituido por horcones (columnas de troncos con raíces quemadas) y armaduras de par y nudillo (tijeras), que obedeciendo al mismo concepto estructural utilizado en la vivienda indígena (cubrir un espacio sin apoyos intermedios) será desarrollado tanto en las viviendas misionales como en las iglesias ${ }^{37}$.

En este sentido, podemos citar a Hans Roth, que considera a la vivienda misional y a la iglesia como integrantes de una misma serie tipologica cuyos prototipos devendrían de la arquitectura griega ${ }^{38}$.

Ademas, Roth considera que existe un paralelismo constructivo y espacial entre la vivienda indígena y las iglesias misionales. Supongo que esto se debe a que la iglesia es entendida como la Casa de Dios (Tuparo: de Tupá: Dios, y roga: casa), un gran salón en el cual la experiencia religiosa no es estrictamente procesional hacia el altar, sino donde se danza y se representan los relatos cristianos, de manera análoga en que se danzaba y se rezaba en las comunidades indigenas ${ }^{39}$.

Por otro lado, el sistema se manifiesta como tradicional en cuanto a la utilización de los horcones y racionalizado en función de la construcción por lances o modulos ${ }^{40}$.

Lo que constituye una ruptura es la escala de Ia iglesia, que debe recibir a toda la población; antes, la casa comunal podía albergar macrofamilias de hasta 400 integrantes; a la Casa de Dios asistían de 1.000 a 1.500 personas según las estadísticas de los primeros pueblos.

36 PERASSO, JoSÉ; A. VeRA, JORGE, La cultura guarani en el Paraguay Contemporáneo, RP Ediciones Asunción, s/f.

37 «Hizo una Iglesia tosca de alfarda (viene del árabe: par de una armadura) por ejercitar las lecciones que VR nos dí, hízola en obra de 20 de nudillo y nuestra casa de la misma manera y como los indias no han visto cosa semejante...*. RUIZ MONTOYA, ANTONIO SJ, Jesuitas e Bandeirantes no Guayrá, int. J. Cortesao, Bib. Nacional, Rio de Janeiro, 1951. Nudillo: palo atravesado y asegurado en las dos patas de las tijeras del caballicte de los edificios rústicos para impedir que abran a cierre.

3B ROTH, HANS, «La habitación indigena en Chiquitosn, en Las misiones jesuíticas de Chiquitos, P. Querejazo Comp. Fundación BHN, La Paz, 1995.

39 ALEXANDER, RICARDO JESSEEN, El barroco guarani (la estructura del espacio arquitectónico), Exposición Barroco Latinoamericano, Museo Nac. de Bellas Artes/FAU, Buenos Aires.

40 ehicimos con ayuda de los indios de otras reducciones un lance de iglesia de 40 pies (...) añadimos segundo y tercero lance a la iglesia que tiene ya mas de 150 pies de largo...*, de Carta Anua (1626-1627) del P. Provincial Mastrillos Durán en «Documentos para la Historia Argentina», Tomo $\mathrm{XX}$, op. cit.

Missionalia Hispanica Hispania Sacra 49 (1997) 
De esta manera se especializa la función religiosa, segregando lo sagrado de lo profano y el cambio de escala es resaltado como una expresión del poder de Dios ${ }^{41}$.

\section{c) Los muros del cerramiento}

La estructura de palos hincados de takuara o bambú (takuarusú) de la ya mencionada og jekutu, cortados y atados con ysypó o lianas y cruzadas por tacuarillas es, desde mi punto de vista, una pared susceptible de ser embarcada.

Esta técnica de embarcar una estructura o esqueleto de entramada de madera es conocida como pared francesa y fue introducida como una novedad por los jesuitas ${ }^{42}$. El padre Roque González de Santa Cruz refiere que «tratábamos de hacer una pequeña iglesia que con ser baja y cubierta de paja, estos pobrecitos lo son tanto, que les parecía palacios reales y mirando hacia el techo hacían milagros; ambos embarrábamos a ratos, para enseñar a los indios, que aún eso no sabían, acabóse para el día de nuestro Santo Padre Ignacio del año pasado de $1615 \ldots{ }^{43}$

Si bien Lozano ${ }^{44}$ describe la vivienda indígena previa al contacto como «chozas de palo y barro tachadas de paja...» y Cardiel ${ }^{45}$ afirmaba que «si a ellos los dejan no han más que un aposento de paredes de palos, cañas y barro...», pienso que prevalecen las fuentes del siglo XVII.

41 «la grandeur et la beauté de ces edifices charment les Indien, et leur donnent une haute idée de notre sainte Religion...», de «Lettre du Pere Nyel au R. Pere Dez de la mesme Compagnie... (1705)», en Lettres edifiantes, Paris, 1708.

42 Torchis: du latin torquere - tordre - Mortier composé de terre grasse et de paille, oul de foin coupé. Le torchis est tassé sur place, entre les colombages de: LEMAHIEW, J., Maison paysannes de France, Association de Sauregarde Patromoine Rural, Paris, 1995. Conocido en América como tapia francesa o estanteo, no confundir con la pared de tapia conformada con encofrado deslizante de madera. Habria que estudiar si el «Bapareques (del taíno bahareque) (pared o tapia de zarzo embarado) no tiene alguna influencia del «torchis» (ver Diccionario de Americanismos, Muchinik Ed., Buenos Aires, 1996.

43 ken viendo como los indios nos cobraron amor tratamos de hacer una pequeffa iglesia y con. serlo y baja, y cubiertos de paja estos pobrecitos lo son tanto que le parecian palacios reales, ymirando hacia el techo hacían milagros y ambos embarrábamos a ratos para ensefiar a los indios que aún eso no sabian...", de GONZÁl.EZ SANTA CRUZ, ROQUE SJ, (Carta Anua del Padre R. González de Santa Cruz y otros documentos), DIAZ DE BEDOYA y GómEZ RODAs Ed., Asunci6n,1983.

44 LOZANO, PEDRo SJ, Historia de la Conquista del Paraguay, Rlo de la Plata y Tucumain, Casa Ed. Imprenta Popular, Buenos Aires, 1873.

45 CARDIEL, JOSÉ SJ, op. cit. 
La pared de barro se relaciona íntimamente con el techo a dos aguas que la debe proteger de la lluvia y las altas temperaturas que, a su vez, es una consecuencia de la armadura introducida por los jesuitas.

Además, su utilización hace innecesario el acondicionamiento interior con fogatas para enfrentarse al frío del invierno recibido en desnude $z^{46}$.

De esa manera, podríamos aplicar el concepto de continuidad al desarrollo de una técnica constructiva conocida parcialmente por los propios indígenas.

En concepto de ruptura lo debemos considerar en cuanto al cambio de conformación formal determinado por el techo a dos aguas y a la aparición de las galerías exteriores, innecesarias en la antigua y directa relación que tenía la vivienda indigena con la arboleda.

Por último, la pared maciza tiene relación con la permanencia y el afincamiento de los indígenas por tiempos más largos a los acostumbrados.

La preparación y estacionamiento de la argamasa hecha con un barro arcilloso y paja implicaba la inversión de fuerza productiva, imposible de considerar en una economía de subsistencia.

\section{d) La durabilidad}

El desgaste de las capas fértiles implicaba, dadas las técnicas agrícolas implementadas, la mudanza de las sementeras cada cuatro o cinco años ${ }^{4}$. La abundancia de materiales de recolección hacía innecesario el transporte de la vivienda, salvo en el caso de los materiales de cerramiento denominados «esteras», que eran empleites de hojas de palmeras, llamadas «yuyí», cuyo uso continúa hasta el presente ${ }^{48}$.

En una carta anua, de 1627 , se dice que «todo es monte cerrado sin campo ninguno, si no es alguna mancha pequeña de dos o tres cuadras, en que se cría aJguna paja para cubrir las casas, aunque pocos unas della, porque tienen otra cosa a manera de palmas que se llama yuyí con la cual hacen empleites (envolver-enredar), de cinco o seis palmos de ancho y por la parte de abajo que es dentro de la casa parecen esteras y no tienen goteras, lo cual fortalecido con

* Inercia térmica: proceso por el cual los muros absorven el calor durante el día y a la noche lo refractan en el interior de la vivienda.

47 Ver MEIIA, BARTOMEU SI, op. cit.

48 La casa og jekutu tiene construida la base deJ techo con un trenzado de hojas de palma pindó jata'i (butia jatai) y viras o chalas de avatí en lécnica graduada «tatuape* caracteristicas de los cestos de ajo. Para la cubierta se utilizaba hojas de palma jejy (euterpr edulis Mart) de Perasso-Vera, op. cit. 
el fuego que ordinariamente hacen debajo dura cinco o seis años y sin fuego dicen que en breve tiempo se pudren... ${ }^{49}$

Esta precariedad de la vivienda indígena también tenía que ver con su concepción de la muerte, ya que en caso de fallecimiento de uno de los miembros de la familia, era sepultado en el lugar y quemada la vivienda para evitar la acción del anguery (alma mala) sobre los seres vivos ${ }^{50}$.

El revolucionario cambio que significó la utilización de las herramientas de hierro, introducidas por los jesuitas, propició la continuidad de los asentamientos poblacionales. Esta radicación exigía otro tipo de vivienda con los elementos que ya hemos explicado en los puntos anteriores, que modifica sustancialmente el microclima del espacio interior. A los altos techos y las cámaras de aire, encerradas por cielorrasos, la ventilación cruzada a través de escasa -pero estratégicas- aberturas y la inercia térmica de paredes de grandes espesores $(0,80$ a $1,00 \mathrm{~m})$ se agregó la utilización de vestimentas. Prescindir de las fogatas en el interior de las viviendas permitio la utilización de paja para los techados, pero, de cualquier manera, se hicieron prontamente necesarias las tejas ${ }^{51}$, ya que los indigenas misionales usaban fuego para cocinar dentro de las viviendas ${ }^{52}$.

El fuego estaba íntimamente relacionado con la vivienda en la lengua, como se puede colegir en la voz tap 'yi, que designa un simulacro de casa caracterizado por el fuego (tatá: hogar), (tatá-ypy: lugar del fuego), (tapera-tatapuera: lugar en que ha habido fuego; es decir, que ha sido habitado por gente) ${ }^{53}$.

4 MASTRILLO DURÁN, NICOLẢS SJ, op. cit.

so Anguery es una de las almas que dicen tener los ñandéva Sus características están relacionadas con lo malo; después de la muerte ronda a los seres vivos para atormentarlos, por lo cual es necesario mudar de lugar la vivienda o por lo menos la disposición de las puertas de entrada a las viviendas de los familiares. Ver SCHADEN, ECON, op. cit.

s) «a partir de la década de 1640, la multiplicación de los incendios hizo que se comenzara a introducir cl techado con tejas cocidas en reemplazo de las cubiertas de paja y cafias...», de MAEDER, ERNESTO, \&La población de las Misiones de Guaranies (1641-1628), Reubicación de los pueblos y consecuencias demograficas», en Estudios Ibero-Americanos, Vol. XV, No 1, PUCRS, Port Alegre, 1989.

52 «el gobernador Doblas opinaba en 1785 (...) estaban tan inmundas, negras, llenas de humo y hediondez, que es repugnante entrax en ellas pues con un solo fogón guisan la comida, se calientan y alumbran*, de GuItérREZ, RAMÓN, Evolución Urbanistica y Arquitectónica del Paraguay, Ed. Comuneros, Asunción, 1983.

53 UNKEL, CURT, (Nimuendaju) aLos mitos de creación y de destrucción del mundo como fundamento de la religión de los Apapokuva-Guarani», Centro Amazonico de Antropol., Lima, 1978.

Missionalia Hispanica Hispania Sacra 49 (1997) 
e) La forma exterior

Staden define la forma exterior de la vivienda indígena como «la boveda de una bodega.... ${ }^{54}$. Estas características las podemos encontrar en los dibujos de varios cronistas del siglo XVI, como en la obra de Uirico Schmidel (grabado 9 del capítulo 28, Ed. de Levinus Hulsios de 1599) o el libro de Jean de Lery Viajem a terra do Brasil ${ }^{55}$.

Según Unkel, el mito de Kaxinagua menciona una casa acanoada que escapa del diluvio y sobrevive a él (aunque al investigador no le parece un relato originario sino influido por el cristianismo).

También los actuales avá-katú-eté vinculan la vivienda con el diluvio a través del cesto que hizo Jar'yi piré con un trenzado de hojas de palmera ${ }^{56}$.

Es evidente que la introducción del techo a dos aguas cambia sustancialmente el aspecto exterior de la vivienda.

De esa manera se diluyen los componentes míticos orignarios.

Sin embargo, también es evidente que existe una apropiación por parte de los indígenas misionales de la tipología creada.

En el caso del pueblo formado por cacicazgos fugitivos de distintas reducciones jesuíticas, en 1736 la disposición de la vivienda adoptada, presumiblemente era la misma que la de los pueblos misionales ${ }^{57}$. También en los pueblos post-misionales, como San Javierito en Chiquitos, la tipología de vivienda adoptada provenía de la experiencia misional realizada.

Si tenemos en cuenta que grupos étnicos del tronco lingüístico tupí-guaraní, como los chiriguanos y los guarayos ${ }^{58}$, por intermedio de los contactos interétnicos habían adoptado otras tipologías de construcciones provenientes del tronco lingüístico arawak y habían seguido manteniendo su etnocentrismo es posible considerar que las características de continuidad y ruptura deberían ajustarse a las que los propios grupos étnicos incluyeran o excluyeran en sus procesos de transformaciones culturales, siendo así que - posteriormentecontinuaron reconociéndose como grupo étrico ${ }^{59}$.

\footnotetext{
S4 SCHADEN, EOON, op. cit.

sS LERY, JEAN DE, op. cit. SCHMIDEL, ULRICO, Derrotero y viaje al Rlo de la Plata y Paraguay, Ed. Napa, Asunción, 1983.

56 BARTOLOMÉ, MigUEL, Chamanismo y religión entre los Avá-Kath-eté, Centro Est. Antrop. de Ja Univ. Cat6lica, Asunción, 1991.

s7 FURLONG CARDIFF, GUILLERMO, Nussdorfer y su $9^{\circ}$ parte, Ed. Theoria, Buenos Aires, 1971.

sa SUSNIK, BRANISLAVA, op, cit.

s9 BARTH, FREDRlL, Los grtupos étnicos y sus froneras, Fondo de Cultura Económica, México, 1976.

Missionalia Fispanica

Hispania Sacra 49 (1997)
} 


\section{CONCLUSIONES}

En mi trabajo he intentado poner en valor la interrelación de las categorías conceptuales referentes a la arquitectura de la vivienda indigena y otros aspectos de la cultura guaraní, como los hábitos de subsistencia. Este encadenamiento, aunque no es novedoso en los estudios etnológicos, no había sido implementado con sistematicidad en los estudios de historia de la arquitectura de las misiones jesuíticas.

De esta manera un elemento arquitectónico no da cuenta autónomamente de su significado sino que éste es determinado por un contexto de significación que varía con el paso del tiempo ${ }^{60}$.

En consecuencia, la categoría de continuidad no relaciona términos iguales sino semejanzas o vinculaciones metafóricas.

Esto quiere decir que un sistema estructural pudiera haber sido sustjtuido por otro distinto del punto de vista de su mecánica de funcionamiento, pero que reprodujera análogamente el esquema espacial anterior; o se variaba la escala pero se conservaba la tipología; o se continuaban usos del espacio segregando y especializando los sitios arquitectónicos.

Así, la danza, una forma básica de la religiosidad y de la experiencia indígena del espacio, va a tener alguna forma de continuidad dentro de las iglesias y, por otro lado, una categoría cultural ajena a la etnicidad de los guaraní, como la vida privada podrá tener aceptación como delimitación material de una situación previamente ya establecida.

Cuando el padre Roque González de Santa Cruz se refiere a las nuevas viviendas y dice que «aunque entendimos que no lo tomarían bien, por quererles quitar algo tan antiguo como sus antepasados, no fue asi; antes lo tomaron muy bien, están muy contentos en sus casas nuevas.... ${ }^{61}$, estaba conformando Ia metodología evangelizadora que le iba a permitir a la Compañía de Jesús la conquista espiritual de un vasto espacio geográfico.

Como ha afirmado Bartomeu Meliá «por una parte las nuevas casas marcan una ruptura con la materia precedente; por otra, el cambio es tal que no provoca ruptura.... ${ }^{62}$

GO MELIÁ, BARTOMEU SJ, op. cit.

ol «las dimensiones e importancia relativa de los diversog ámbitos (religioso, social, político, económico, etc.) variaron a lo largo de las etapas historicas de cada población...», de CARBONEL DE MASY, RAFAEL, SJ, «Participación indígena en las misiones jesuíticas guaraniesn, en Un camino hacia la Arcada, Min. Espanol de Asuntos Ext., Madrid, 1995.

62 González de SANTA CRUZ, ROQUE SJ, op. cil. 


\section{GLOSARIO DE TÉRMINOS EN CASTELLANO, UTILIZADOS COMO CATEGORIAS CRÍTICAS}

Bajareque (del taíno bahareque) (América Central, Colombia, Ecuador, Rep. Dominicana y Venezuela). En época colonial se usó también en el noroeste argentino: pared o tapja de zarzo embarrado.

Colectivos (del latin collectivus). Formado o constituido por varios individuos o perteneciente o relativo a ellos. Dícese del nombre que expresa en singular la reunión de individuos o cosas de la misma especie, o conjunto o muchedumbre.

Familia: gente que vive en una casa bajo la autoridad de una persona que es jefe o cabeza de ella. Conjunto de individuos de un linaje/conjunto de individuos de una condición común.

Privado (del latín privatus): que se hace familiar y domésticamente y sin ceremonia/Particular y personal de cada uno.

Promiscuidad: mezcla o confusión.

Promiscuo: mezclado indistintamente.

Topia (del frabe tabiya): cada uno de los trozos de pared que de una sola vez se hacen con tierra amasada y apisonada en una horma.

Tapia: víeja palabra comán a las tres lenguas romances peninsulares y a la lengua de $O_{c}$ y propagada desde España al árabe y hasta el turco; en catalán se halla desde 1169 y en mozárabe desde el siglo $x$. Hay que suponer una antigua base hispanica.

Tapia: en nombre arábigo según el Padre Guadix y está cortompido de tapia que vale pared de tierra. Tapiales, los moldes o tableros con que se hacen las cajas de las tapias.

Tapia: de la onomatopeya «tapm, que significa arcilla.

Tapia: cloison de terre.

Tapia: palabra francesa que se usaría en el siglo xvitI y que significa árbol o tabla.

Tapia (en Cuba, Honduras, Guatemala): bajareque.

Vivienda (del latín vivienda, de vivendus, de vivere, «vivir»): morada, habitación, domicilio, género de vida o modo de vivir.

\section{BiBLIOGRAFIA}

COROMinas, JuAn, Diccionario crítico etimológico de la lengua castellana, ed. Gredos, Madrid, 1976.

COVARRUBias, Sebastí́n DE, Tesoro de la lengua castellana o española (1611), Ed. Alta Fulla, Barcelona, 1993.

FerRecio PoDestá, MARIo, El diccionario académico de americanismo, Univ. de Chile, Santiago, 1978.

GARCIA DE DIEGO, VICENTE, Dicionario etimologico español e hispánico, Espasa-Calpe, Madrid, 1985.

REAL ACADEMIA Española, Diccionario de Autoridades (ed. facsímil), Ed. Gredos, Madrid.

Missionalia Hispanica

Hispania Sacra 49 (1997) 
REAL ACADEMia ESPAÑola, Diccionario de la lengua española, RAE, Madrid, 1970.

S/A, Diccionario de americanismos, Muchnik Ed., Buenos Aires, 1966.

TERRERos Y PANDO, ESTEBAN, Diccionario Castellano con las voces de Ciencia y Artes, Madrid, 1788.

GLOSARIO de TÉRMINOS EN FRANCÉS UTIL.ZADOS COMO CATEGORÍAS CRITICAS

Cloison: tabique, pared delgada de madera o mampostería.

Torchis: argamasa hecha de barro y paja para hacer tapiales.

\section{BtBLOOGRAFÍA}

LJTTRÉ, E., Dictionnaire de la langue Frangaise, Ed. Hachette, París, 1863.

SALví, VicenTe, Nuevo Diccionario Francés-Español, Lib. de Garnier Hnos., Paris, 1880.

\section{GLOSARIO DE TERMINOS EN GUARANI UTILIZADOS COMO CATEGORIAS CRITICAS}

Mburuvichá: jefe aldeano.

Oga-Kog: casa comunal.

Teko'a: aldea formada por la asociación por parentesco polltico de los pequeños tey'y.

Te'yi: pueblo, muchedumbre.

Teyy: banda petrilineal y a la vez, casa comunal.

Yecutí: hincarse.

Yi: resistente.

$Y u$ : venida, aguja, espina, aguijón.

BiBLIOGRAFIA

DACUNDA DIAZ, M. RICARDO, Gran diccionario de lengua guarani, edic. Ocruxares, Buenos Aires, 1989,

Peralta, ANSElmo Jover, Diccionario Guarant-español y español-guarant, Ed. Tupa, Buenos Aires, 1951.

GLOSARIO DE UNIDADES DE MEDIDAS UTILIZADAS

1 braza -2 varas.

1 pie castellano $-0,28$ metros.

1 vara $=4$ palmos -3 pies. 
1 vara $-835 \mathrm{~mm}$ y 9 décimas.

(Castilla)

\section{Glosario de siglas UTH.ZADAS}

AGN: Archivo General de la Nación, Buenos Aires, Argentina.

CA: Cartas Anuas de la Provincia del Paraguay, Chile y Tucumán de la Compañía de Jesús (op. cit.).

MCODA: Manuscritos da Colecao de Angelis (op. cit.). 